\title{
Neurophysiological findings in the hereditary presenile dementia characterised by polycystic lipomembranous osteodysplasia and sclerosing leukoencephalopathy
}

\author{
HPA HAKOLA, VSJ PARTANEN \\ From the Niuvanniemi Hospital, Kuopio, and the Department of Clinical Neurophysiology, University of \\ Kuopio, Finland
}

SUMMARY 17 patients suffering from the presenile dementia characterised by polycystic lipomenbranous osteodysplasia and sclerosing leukoencephalopathy were studied neurophysiologically. Noteworthy findings were diffuse slowing, the accentuation of $6-8 \mathrm{~Hz}$ parasagittal activity, slowing of the dominant occipital rhythm and, in the late phase when 13 of patients got epileptic seizures, there was paroxysmal activity in the EEG.

Polycystic lipomembranous osteodysplasia with sclerosing leukoencephalopathy is a rare hereditary form of presenile dementia with changes both in brain and bones. ${ }^{1-4}$ It is caused by an autosomal recessive gene. ${ }^{3}$ Eighty patients have been documented: 20 in Finland, 46 in Japan, nine in Sweden and five in USA. ${ }^{5-8}$ The majority of Finnish patients are inhabitants of the middle-eastern part of the country. ${ }^{3}$

Childhood is mostly symptomless (the latent phase). Around the age of 20 years patients suffer from pains and tenderness in the ankles and wrists and later from fractures (the phase of skeletal symptoms). The radiographic appearance is diagnostic. $^{3910}$ Cystic rarefactions are situated in the bones of the extremities symmetrically. The cysts are filled with partly necrotic fat tissue containing peculiar ultrastructurally characteristic autofluorescent membranes. Histochemically, fatty acids and their polymerisation products seem to be an essential component of these membranes. ${ }^{11}$ Neuropsychiatric symptoms appear insidiously during the fourth decade of life and gradually form a disease picture, which consists of dementia with prefrontal syndrome, signs of upper motor neuron involvement, apractic-aphasic symptoms and myoclonic

Address for reprint requests: HPA Hakola, MD, Niuvanniemi Hospital, Kuopio 24, SF-70240 Finland

Received 15 December 1982.

Accepted 17 January 1983. twitches (the early phase of neuropsychiatric symptoms). ${ }^{23}$ These symptoms progress steadily and are later accompanied with other symptoms, especially epileptic seizures (the late phase). Death follows around the age of 40 years. ${ }^{3}$ Air encephalography and CT scan have revealed diffuse generalised brain atrophy. ${ }^{1213}$

Macroscopic examination of the brains of six Finnish cases revealed more or less marked atrophy and greyish discoloration of the central parts of the hemispheric white matter, particularly of the frontal and temporal but to some extent also of the parietal lobes. The cortex of these regions was generally much better preserved than the white matter. A variable degree of atrophy was noticed in the caudate nuclei of all but one case who died accidentally at an early stage of the disease. Light microscopic studies on the affected white matter showed pronounced degeneration and loss of myelin, a variable degree of axonal degeneration with formation of spheroids, increase in number of astrocytes and fibrillary gliosis. ${ }^{14-16}$

In a series of eight typical patients a symmetrical, synchronous and episodic 6-8 $\mathrm{Hz}$ activity was described by Hakola as a characteristic EEG finding. ${ }^{3}$ Increased amount of diffuse theta and delta activity was also observed. This general disturbance has also been noted in case reports by other authors. ${ }^{513}{ }^{17-18}$ Reports about the irritative EEG açtivity are scanty. EMG, evoked potential and nerve conduction studies have not previously been reported in the literature. 
Table 1 The typical neuropsychiatric symptoms and epileptic seizures of 17 patients at the last EEG recording.

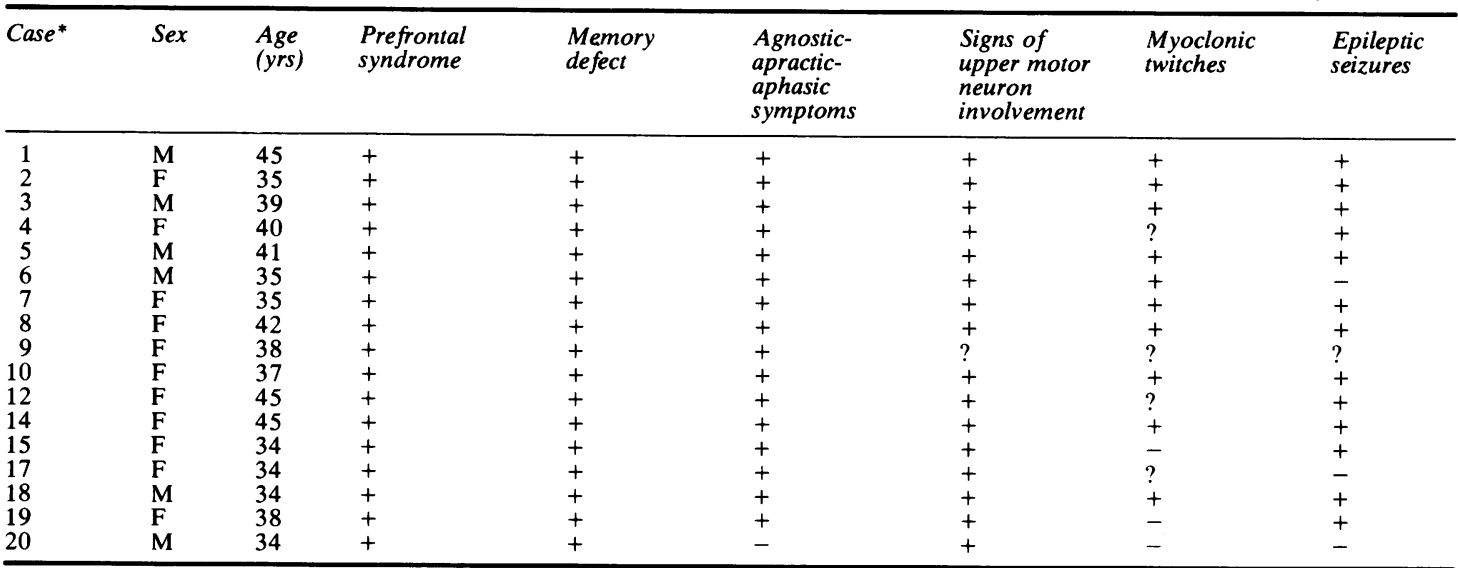

*The cases are numbered as in Järvi, Hakola and Sourander, in preparation.

The aim of this study was (a) to analyse EEG alterations in this disease, especially the EEG dynamics at different stages of the disease during follow-up of considerable length, and (b) to search for possible signs of dysfunction in the peripheral nerves and muscles with other neurophysiological techniques.

\section{Material and methods}

The material consists of 17 patients, 11 women and six men with typical polycystic lipomembranous osteodysplasia with sclerosing leukoencephalopathy. All patients had characteristic cystic changes in bones on radiological examination. EEG recording was performed on all patients at least once and was in most of the cases repeated. At the first recording seven patients were in the early phase of

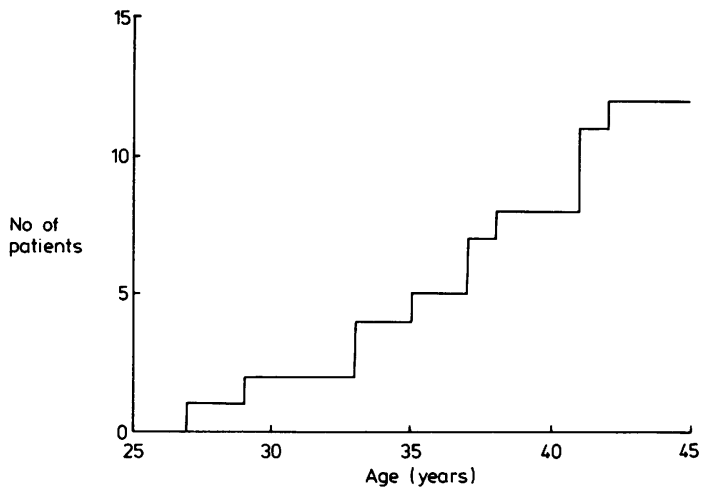

Fig. 1 The cumulative graph of the beginning of the epileptic seizures. (From the total material of 17 patients four do not have seizures. Three of them have died at ages of 36,38 and 39 years. One patient is alive, age 34 years.) neuropsychiatric symptoms and 10 patients in the late phase. At the last recording figures were respectively two and 15 and with few exceptions patients showed all typical neuropsychiatric symptoms of the disease (table 1). The frequency of epilepsy on patients increased progressively after the age of 25 years. All patients who had reached the age of 40 years, had suffered from epileptic seizures before their death (fig 1). Seizures were observed on 13 patients. These were of grand mal type in all patients.

Twelve of our patients died and six of them have had necropsies. Results of neuropathological examinations as well as details of neurological and psychiatric findings will be published separately in a monograph (Järvi, Hakola and Sourander, in preparation).

EEG recordings were performed in three different hospitals over 25 years, mostly with the international $10-20$ system. Photostimulation was included in the studies. All 37 EEG recordings were analysed by the authors. The dominant occipital rhythm was determined. The abundance of rhythmic parasagittal $6-8 \mathrm{~Hz}$ activity was observed $(-=$ no, $\pm=$ doubtful finding, $+=$ slight,$++=$ moderate, $+++=$ marked) as well as the amount of diffuse slow activity. The occurrence of paroxysmal activity and asymmetric findings was noted. In four patients tremor of the upper extremity was recorded during the EEG examination.

In six patients an EMG study of the anterior tibial, extensor digitorum brevis and other muscles was performed with DISA 1500 EMG equipment and concentric needle electrodes (diameter 0.45 or $0.30 \mathrm{~mm}$ ). The occurrence of spontaneous activity as well as the duration, amplitude and polyphasy of the motor unit potentials was observed audiovisually. In some patients the accurate analysis of motor unit potentials was difficult because of poor co-operation.

Sensory conduction velocity (SCV) of the radial, median and superficial peroneal nerve was measured with an antidromic technique using surface electrodes. In some cases SCV of the ulnar and sural nerves was included. Motor conduction velocity (MCV) of the median, ulnar and deep 
peroneal nerves was measured with surface electrodes. The F-response latency of these nerves was also determined. In three patients we measured the $\mathrm{H}$-reflex latency in the posterior tibial nerve.

In two patients (numbers 8 and 20) a somatosensory evoked potential study was performed. The left median nerve was stimulated at the wrist with $5 \mathrm{~Hz}$ rectangular pulses $(0.3 \mathrm{~ms} 5.0 \mu \mathrm{A})$ so that small twitches of the thenar muscles were observed. The somatosensory evoked potentials were recorded at the elbow, Erb's point, 2nd cervical vertebra and contralateral somatosensory cortex. The cortical potentials were recorded with small platinum needle electrodes (DISA $25 \mathrm{C} \mathrm{04}$ ), other potentials with surface plate electrodes (DISA $13 \mathrm{~K} \mathrm{60)}$ ). The potentials were averaged 200 times with Tracor Northern TN 1710 multichannel analyzer after amplification with DISA 1500 EMG amplifiers.

\section{Results}

\section{EEG (table 2)}

The earliest alteration in EEG was a slight accentuation of diffuse slow activity and mild to moderate accentuation of $6-8 \mathrm{~Hz}$ rhythmic parasagittal activity. When the disease progressed, the amount of diffuse slow activity increased. Also the amount of 6-8 parasagittal activity increased at first, but in the late phase of the disease it tended to diminish again. The dominant occipital rhythm slowed gradually down (table 2). When the frequency of dominant occipital rhythm in the first recording at an age below 35 years was compared to the last recording at an age of
Table 2 EEG dynamics in two patients (general disturbance)

\begin{tabular}{lcll}
\hline $\begin{array}{l}\text { Age in } \\
\text { recording }\end{array}$ & $\begin{array}{l}\text { Dominant occipital } \\
\text { rhythm }(\mathrm{Hz})\end{array}$ & $\begin{array}{l}6-8 \mathrm{~Hz} \\
\text { activity }\end{array}$ & $\begin{array}{l}\text { Diffuse slow } \\
\text { activity }\end{array}$ \\
\hline $\begin{array}{l}\text { Patient } 1 \\
31\end{array}$ & $10-11$ & \pm & \pm \\
35 & $9-11$ & + & + \\
38 & $9-10$ & + & ++ \\
42 & $6-8$ & + & +++ \\
45 & $5-6$ & \pm & +++ \\
Patient 2 & & + & + \\
31 & $8-9$ & + & + \\
32 & $7 \cdot 5-8 \cdot 5$ & ++ & ++ \\
36 & $6-8$ & ++ & +++ \\
38 & $6-8$ & \pm & +++ \\
41 & $6-7$ & - & +++ \\
42 & $5-7$ & & + \\
\hline
\end{tabular}

more than 35 years, a significant decrease of the mean frequency was observed (mean frequency 9.0 $\mathrm{Hz} \mathrm{SD} 1.0$ in the first recording and $7.2 \mathrm{c} / \mathrm{s}$ SD 1.6 in the last recording $(p<0.01)$, number of recordings was 10 in both groups).

Paroxysmal activity was usually not present before an advanced stage of the disease (table 3 ). In five of 17 patients we observed paroxysmal slow activity and in four either multifocal spike and wave complexes or generalised spike and wave paroxysms (fig 2). Asymmetric findings were rare. In two patients occasional asymmetric slow activity was observed in the right hemisphere and in two patients there was a predominance of slow waves in the left

Table 3 The most marked EEG findings at the last EEG recording. The age of patients at the recording and at first seizure is also represented.

\begin{tabular}{|c|c|c|c|c|c|c|}
\hline $\begin{array}{l}\text { Patient } \\
\text { number }\end{array}$ & $\begin{array}{l}\text { Age at } \\
\text { recording } \\
(y r)\end{array}$ & $\begin{array}{l}\text { Age at } \\
\text { first seizure } \\
(y r)\end{array}$ & $\begin{array}{l}\text { Dominant } \\
\text { occipital } \\
\text { rhythm } \mathrm{Hz}\end{array}$ & $\begin{array}{l}6-8 \mathrm{~Hz} \\
\text { rhythm }\end{array}$ & $\begin{array}{l}\text { Diffuse } \\
\text { slow activity }\end{array}$ & $\begin{array}{l}\text { Paroxysmal activity, } \\
\text { spike and wave } \\
\text { complexes }\end{array}$ \\
\hline $\begin{array}{l}1 \\
2 \\
3 \\
4\end{array}$ & $\begin{array}{l}45 \\
35 \\
39 \\
40\end{array}$ & $\begin{array}{l}41 \\
33 \\
41 \\
42\end{array}$ & $\begin{array}{l}5-6 \\
5-7 \\
8-9 \\
4-8\end{array}$ & $\begin{array}{l} \pm \\
+ \\
+ \\
+\end{array}$ & $\begin{array}{l}+++ \\
++ \\
+ \\
+\end{array}$ & $\begin{array}{l}- \\
- \\
\overline{\text { slow wave }} \\
\text { paroxysms }\end{array}$ \\
\hline 5 & 41 & 41 & $5-8$ & ++ & ++ & $\begin{array}{l}\text { slow wave } \\
\text { paroxysms }\end{array}$ \\
\hline 6 & 35 & - & $9-10$ & +++ & ++ & $\begin{array}{l}\text { frontal spike-wave } \\
\text { paroxysm }\end{array}$ \\
\hline $\begin{array}{l}7 \\
8 \\
9\end{array}$ & $\begin{array}{l}35 \\
42 \\
38\end{array}$ & $\begin{array}{l}42 \\
37 \\
-\end{array}$ & $\begin{array}{c}8 \cdot 5-10 \\
5-7 \\
10-11\end{array}$ & $\begin{array}{l}+ \\
\pm \\
\pm\end{array}$ & $\begin{array}{l}+ \\
+++ \\
\pm\end{array}$ & $\begin{array}{l}- \\
- \\
-\end{array}$ \\
\hline 10 & 37 & 38 & $8 \cdot 5-10$ & + & + & theta paroxysms \\
\hline 12 & 45 & 46 & 7-9 & + & ++ & - \\
\hline 14 & 45 & 35 & $8-9$ & + & ++ & $\begin{array}{l}\text { slow wave and spike- } \\
\text { wave paroxysm }\end{array}$ \\
\hline 15 & 34 & 33 & $8-9$ & ++ & ++ & $\begin{array}{l}\text { multifocal spike-wave } \\
\text { complexes }\end{array}$ \\
\hline $\begin{array}{l}17 \\
18\end{array}$ & $\begin{array}{l}34 \\
34\end{array}$ & $\overline{29}$ & $\begin{array}{l}8-10 \\
7-8\end{array}$ & $\stackrel{+}{+++}$ & $\stackrel{+}{++}$ & $\begin{array}{l}\text { multifocal spike-wave } \\
\text { complexes and slow } \\
\text { paroxysms }\end{array}$ \\
\hline $\begin{array}{l}19 \\
20\end{array}$ & $\begin{array}{l}38 \\
34\end{array}$ & $\begin{array}{l}27 \\
-\end{array}$ & $\begin{array}{l}6-8 \\
9-10\end{array}$ & $\begin{array}{l}++ \\
+++\end{array}$ & $\begin{array}{l}++ \\
+\end{array}$ & - \\
\hline
\end{tabular}

*Numbering according to Järvi, Hakola and Sourander (in preparation) 


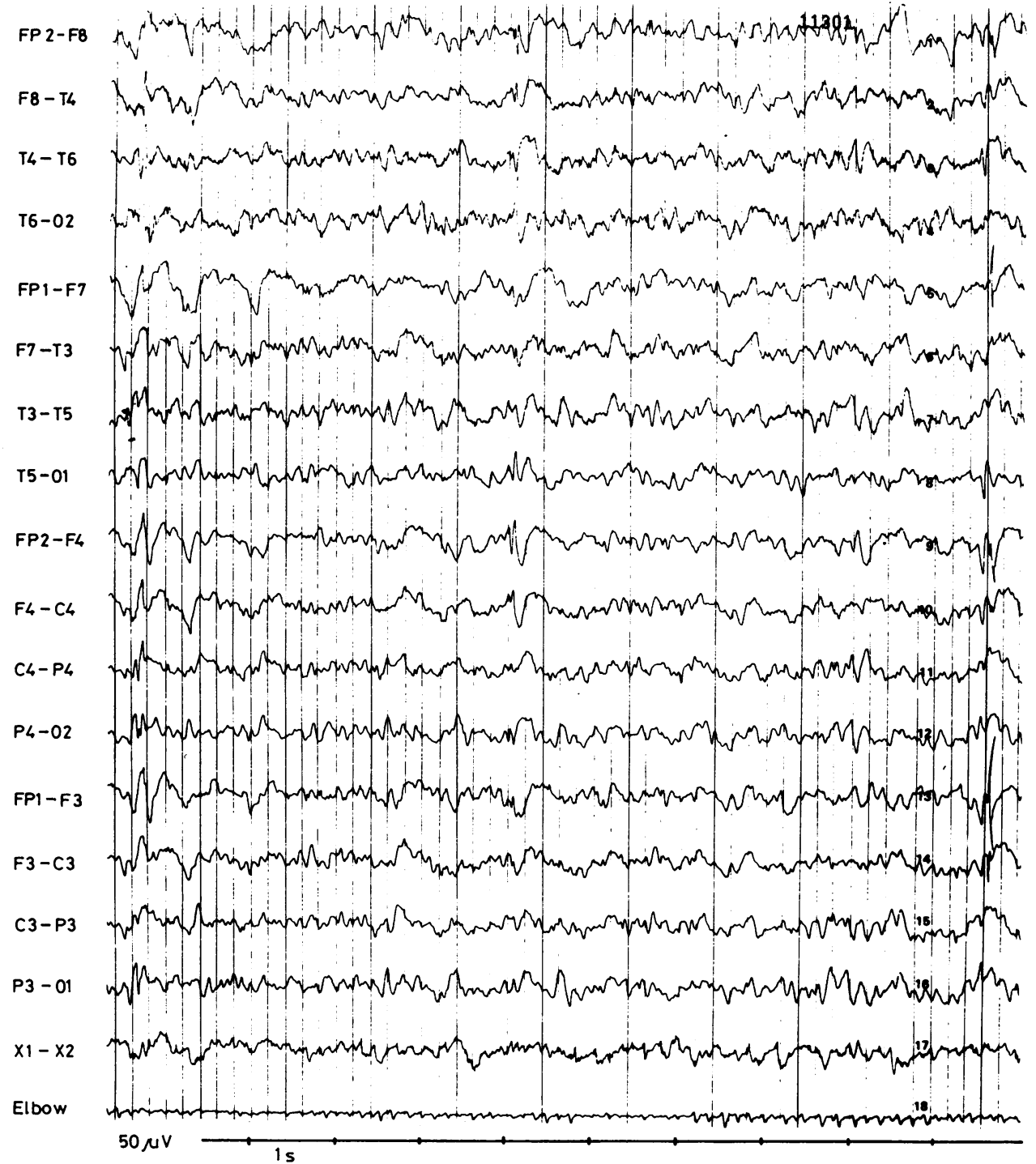

Fig. 2 General disturbance and multifocal spike and wave activity in the EEG of a patient (number 18).

hemisphere. In seven recordings where EEG analysis of sleep was possible, distinct alterations were observed: the sleep EEG patterns (vertexpotentials, K-complexes and sigma activity) tended to be reduced or absent. In tremor recordings we observed $6-8 \mathrm{~Hz}$ tremor in four patients. Evident myoclonic twitches did not appear during recordings.

EMG and nerve conduction studies

In needle EMG three of six patients showed a nor mal EMG in the anterior tibial muscle, two dis- played increased incidence of polyphasic motor unit potentials and one denervation activity and polyphasic potentials. In other muscles increased incidence of polyphasic motor unit potentials was a common finding but denervation activity was present in only two patients in the terminal stage of the disease.

In nerve conduction studies only occasional slightly slow MCV values or increased F-response latencies were observed in two patients. SCV values were normal.

In the somatosensory evoked potential study of 
one patient (number 20) the latencies of the responses at elbow, Erb's point, 2nd cervical vertebra and somatosensory cortex were within normal limits. However, in another patient (number 8) in the late phase of the disease an increase of the latencies of cortical somatosensory potential peaks N 19 and $P 22$ was observed, when the potentials were compared either with those of a female control person of similar age and height or with our female control material $(n=33)$, where the influence of height on the latency values could be eliminated.

\section{Discussion}

The most marked EEG characteristics of polycystic lipomembranous osteodystrophy with sclerosing leukoencephalopathy are the accentuation of diffuse slow activity, accentuation of $6-8 \mathrm{~Hz}$ activity in the parasagittal areas but often also spreading to the anterior-lateral areas of the brain, slowing of the dominant occipital rhythm and in late stages paroxysmal slow activity and multifocal or generalised spike and wave activity. The general slowing resembles that in the dementia of the Alzheimer type. ${ }^{19}$ The accentuation of 6-8 Hz parasagittal activity may be more marked in polycystic lipomembranous osteodysplasia with sclerosing leukoencephalopathy. It is interesting, that this kind of alteration has been detected also in some children of such patients. ${ }^{3}$ Rhythmic 6-8 activity may reflect a disturbance in subcortical brain structures. Gloor $e t$ al. have claimed that the accentuation of diffuse slow activity correlates with lesions of the white matter of the brain. ${ }^{20}$ Our findings support this concept.

Paroxysmal activity, especially multifocal or generalised spike and wave activity, reflects epileptogenic cortical foci and may be correlated with epileptic seizures of the polycystic lipomembranous osteodysplasia with sclerosing leukoencephalopathy patients. However, the lack of paroxysmal activity did not exclude the occurrence of epileptic seizures. Thus there may also be subcortical irritative foci which may not be seen in the conventional scalp EEG recording. ${ }^{21}$ The irritative EEG alterations were most marked in advanced cases of the disease associated with demonstrable cortical lesions. The paroxysms are of the secondarily generalised type. We think that this disease may serve as a suitable natural model for the studies of secondarily generalised epilepsy. In the late phase, the seizure activity in this disease is one of the highest among brain diseases.

No signs of peripheral polyneuropathy or myopathy was observed on EMG studies. The increased incidence of polyphasic motor unit potentials and denervation activity in some muscles of the patients may indicate a slight involvement of the anterior horn motoneurons. The observations on somatosensory evoked potentials in two patients suggests that the latencies of the cortical responses may be normal in an early stage of the disease, but that delay may occur in the advanced stage of the disease. This finding is compatible with a demyelinating process affecting the upper brain stem and thalamocortical projections. ${ }^{22}$

This disease should be considered in the differential diagnosis of epilepsy in middle age, especially if epilepsy is connected with dementia. For differential diagnosis the EEG findings alone are not conclusive. The diagnosis can be made easily on the basis of radiological examination of bones.

As for the pathogenesis of polycystic lipomembranous osteodystrophy with sclerosing leukoencephalopathy three working hypotheses have been advanced. Järvi has detected vascular degeneration in bones and also in internal organs. ${ }^{11}$ Similar changes have been found in vessels of brain by Sourander. ${ }^{11} 1$ 15 $^{15}$ These authors consider that secondary oedema and nutritional disturbances lead to slowly developing fat necrosis in the bones with membrane condensations and gliosis associated with slight to moderate myelin degeneration of the white matter of the brain. ${ }^{11} 15$ Nasu and other Japanese investigators have found membranous necrosis also in fat tissue of other organs. They suggest that the primary defect is in the metabolism of lipids. ${ }^{5}$ However, chemical studies on lipids and fatty acids in the Finnish cases performed by Svennerholm (personal communication) have produced negative results. Matsushita et al., who recently reported one female case with typical brain changes but without bone lesions, suggested that axonal degeneration is the key phenomenon of the pathogenesis of the disease. ${ }^{16}$ Our results indicate, that axonal degeneration in the peripheral nervous system is not obvious.

\section{References}

1 Järvi OH, Hakola HPA, Lauttamus LL, Solonen KA, Vilppula AH. Cystic capillary-necrotic osteodysplasia. A systemic bone disease probably caused by arteriolar and capillary necroses. Relation to brain affections. In: Abstracts. Seventh International Congress of International Academy of Pathology. Milan: State University of Milan 1968:291-292.

${ }^{2}$ Hakola HPA, Järvi OH, Sourander P. Osteodysplasia polycystica hereditaria combined with sclerosing leucoencephalopathy. A new entity of the dementia praesenilis group. Acta Neur Scand 1970;46 (suppl. 43):79-80.

${ }^{3}$ Hakola HPA. Neuropsychiatric and genetic aspects of a new hereditary disease characterized by progressive 
dementia and lipomembranous polycystic osteodysplasia. Acta Psychiat Scand 1972; (suppl. 232):1-173.

${ }^{4}$ Hakola HPA. Dementia, progressive with lipomembranous polycystic osteodysplasia. In: Vinken PJ and Bruyn GW, eds. Handbook of Clinical Neurology, part 42 Neurogenetic Directory. Amsterdam: North Holland Publishing Company 1981:279-81.

${ }^{5}$ Nasu T. Pathology of membranous lipodystrophy. Asian Medical J 1980;23:701-26.

- Adolfsson R, Forsell Å, Johansson G. Hereditary polycystic osteodysplasia with progressive dementia in Sweden. Lancet 1978;i:1209-10.

${ }^{7}$ Wood C. Membranous lipodystrophy of bone. Arc Pathol Lab Med 1978;102:20-27.

${ }^{8}$ Bird TD, Koerker R, Vlcek B, Leaird BJ, Thorning DR. Brain, bone and fat (BBF) disease: a rare genetic cause of presenile dementia. Neurology (NY) 1982;32:A143.

${ }^{9}$ Laasonen EM. Das Syndrom der polyzystischen Osteodysplasie mit progressiver Demenz. RöFo 1975;122(4):313-316.

${ }^{10}$ Mäkelä P, Järvi O, Hakola HPA, Virtama P. Radiologic bone changes of polycystic lipomembranous osteodysplasia with sclerosing leukoencephalopathy. Skeletal Radiol 1982;8:51-54.

"Järvi OH, Hakola HPA, Sourander P, Kormano M, Nevalainen T, Kalimo H. Polycystic lipomembranous osteodysplasia with sclerosing leukoencephalopathy (PLO-SL). In: Eriksson AW, Forsius H, Nevanlinna HR, Workman PL and Norio PK, eds. Population structure and genetic disorders. London: Acad Press Inc 1980:656-64.

${ }^{12}$ Hakola HPA, Iivanainen M. A new hereditary disease with progressive dementia and polycystic osteodysplasia: Neuroradiological analysis of seven cases. Neuroradiology 1973;6:162-8.
${ }^{13}$ Laasonen EM, Lahdenranta U. Lipomembranous polycystic osteodysplasia with progressive dementia. $J$ Comput Assist Tomogr. 1981;5(4):580-2.

${ }^{14}$ Sourander P. A new entity of phakomatosis: B. Brain lesions (Sclerosing leukoencephalopathy) Acta Pathol Microbiol Scand 1970; (suppl. 215):44.

15 Sourander P, Järvi O, Hakola P, Kalimo H, Nevalainen T. Neuropathological aspects of polycystic lipomembranous osteodysplasia with sclerosing leukoencephalopathy (membranous lipodystrophy). In: International Symposium on the Leucodystrophy and allied Disease. Kyoto: Japanese Society of Neuropathology (in press)

${ }^{16}$ Matsushita M, Oyanagi S, Hanawa S, Shiraki H, Kosaka K. Nasu-Hakola's disease (membranous lipodystrophy). Acta neuropathol (Berl) 1981;54:89-93.

${ }^{17}$ Akai M, Tateishi A, Cheng CH, Morii K, Abe M, Ohno T, Ben M. Membranous lipodystrophy. J Bone Joint Surg 1977;59-A(6):802-9.

${ }^{18}$ Tanaka J. Leukoencephalopathic Alteration in Membranous Lipodystrophy. Acta Neuropathol (Berl) 1980;50:193-7.

${ }^{19}$ Soininen H, Partanen VJ, Helkala ER, Riekkinen PJ. EEG findings in senile dementia and normal ageing. Acta Neurol Scand 1982;65:59-70.

${ }^{20}$ Gloor P, Ball G, Schaul N. Brain lesions that produce delta waves in the EEG. Neurology (Minneap) 1977;27:326-33.

${ }^{21}$ Gloor P, Olivier A, Quesney LF, Andermann F, Horowitz S. The role of the limbic system in experimental phenomena of temporal lobe epilepsy. Ann Neurol 1982;12:129-144.

${ }^{22}$ Chiappa KH, Ropper AH. Evoked potentials in clinical medicine (second of two parts) $N$ Engl $\mathrm{J} \mathrm{Med}$ 1982;306(20):1205-11. 